Case Study

\title{
AZATHIOPRINE INDUCED PANCYTOPENIA-A CASE REPORT
}

\author{
JESLYN MARY PHILIP, PARVATHYPRIYA C., CHRISTEENA GEORGE, MEENU VIJAYAN*
}

Department of Pharmacy Practice, Amrita school of pharmacy, Amrita Vishwa Vidyapeetham, Amrita University, AIMS, Kochi 682041

Email: meenuvijayan@aims.amrita.edu

Received: 21 Oct 2016 Revised and Accepted: 21 Dec 2016

\begin{abstract}
Azathioprine (AZA), a prodrug of 6 mercaptopurine, is an immunosuppressant that can be used as adjunctive therapy with corticosteroids in the treatment of arteritic form of ischemic optic neuropathy. Although myelotoxicity is known to occur while using azathioprine, severe pancytopenia is rarely seen. Patients with thiopurine methyltransferase (TPMT) deficiency are at high risk of developing severe myelosuppression. A 63 year* old female with ischemic optic neuropathy was initiated treatment with oral methylprednisone. As two courses of oral steroids showed no significant improvement, oral azathioprine $25 \mathrm{mg}$ twice daily was added and gradually increased to $50 \mathrm{mg}$ twice daily with relief of symptoms. $6 \mathrm{mo}$ later, she was admitted with acute stroke and lab reports showed low levels of total blood counts or pancytopenia. The patient was put on broad spectrum antibiotics; given injection of granulocyte colony stimulating factor $300 \mathrm{mcg}$ subcutaneously and blood transfusion as correction till counts normalised. She improved over $14 \mathrm{~d}$ and on next follow-up counts were in normal range. Causality was assessed by Naranjo causality assessment scale and a probable relationship was obtained between azathioprine and pancytopenia with a score of 6 . Variations in TPMT activity occurs due to genetic polymorphism. Physicians should be aware of the possibility of myelosuppression while prescribing azathioprine. Frequent blood count monitoring is the most convenient way to avoid this problem where testing for TPMT deficiency is not possible.
\end{abstract}

Keywords: Azathioprine, Pancytopenia, Thiopurine methyltransferase

(C) 2016 The Authors. Published by Innovare Academic Sciences Pvt Ltd. This is an open access article under the CC BY license (http://creativecommons.org/licenses/by/4. 0/) DOI: http://dx.doi.org/10.22159/ijpps.2017v9i2.15801

\section{INTRODUCTION}

Azathioprine, a prodrug of 6-mercaptopurine, is used as an immunesuppressive agent as monotherapy or as an adjunct with other immune-suppressants mainly to prevent organ transplant rejection but also to treat various autoimmune disorders like rheumatoid arthritis, systemic lupus erythematous, various forms of vasculitis and others [1]. The main side effects of azathioprine include hepatotoxicity, haematological toxicities, myalgia and increased susceptibility to infection. Several studies have reported myelotoxicity to be of great concern while using azathioprine. However, severe pancytopenia is uncommon with AZA [2].

Ischemic optic neuropathy is an infraction of the optic disk. The mainstay of treatment of the arthritic form of ischemic optic neuropathy is glucocorticoids. It helps in suppressing inflammation and preventing visual loss and ischemic stroke. However, long-term use of corticosteroids has been associated with significant morbidity. Hence several steroid sparing agents have been investigated for the treatment of giant cell arteritis with methotrexate being the best studied [3]. Studies have demonstrated the ability of azathioprine to reduce the maintenance corticosteroid requirement in patients with autoimmune disorders to help reduce the adverse effects caused by long-term use of steroids [4-6].

\section{CASE REPORT}

A 66 year* old female presented with acute onset of recurrent vision loss in the left eye associated with a headache towards the left side radiating to the neck and occipital region. She was clinically diagnosed to have bilateral ischemic neuropathy. She was treated with two courses of oral methylprednisolone with which vision improved but deteriorated on tapering the dose of steroids. On the increase in a headache and loss of vision, tablet azathioprine 25 mg twice daily was added along with steroids and improvement in a headache was observed. Six months later she has admitted again with the acute cerebrovascular accident. Complete blood count reports showed pancytopenia in view of which azathioprine was withheld. She developed febrile neutropenia for which she was shifted under strict isolation in the intensive care unit for further management.
Routine blood investigations showed a low level of total blood cell count. Peripheral blood smear report showed echinocytes, rouleaux formation and anisocytosis of RBCs. The hemogram showed a haemoglobin drop to $62 \mathrm{~g} / \mathrm{l}(120-150 \mathrm{~g} / \mathrm{l})$, RBC count of $2.3^{*} 10[12] / 1 \quad\left(3.8-4.8^{*} 10[12] / 1\right)$, WBC count of $0.5^{*} 10^{9} / 1$ (4.0$10.0^{*} 10^{9} / \mathrm{l}$ ), febrile neutropenia with neutrophil count of $19.8 \%$ (40$80 \%)$, and platelet count reduced to $25^{*} 10^{9} / 1\left(150-450^{*} 10^{9} / 1\right)$.

She was treated with an injection of granulocyte-colony stimulating factor (G-CSF) 300 mcg subcutaneously till acute neutrophil count was within normal limits, and blood transfusion (single or pooled platelets) as a correction. She was put on broad spectrum antibiotics (injection piperacillin-tazobactam $4.5 \mathrm{~g}$ ) for febrile neutropenia. In view of a stroke she was put on anticoagulation with injection enoxaparin $0.6 \mathrm{ml}$ under strict monitoring of hematological parameters. She responded clinically and improved over $14 \mathrm{~d}$ and on discharge was advised to monitor blood counts at regular intervals. On next follow-up, blood counts were in normal range.

\section{DISCUSSION}

Azathioprine is non-enzymatically converted to 6 mercaptopurine in vivo. Further metabolism involves enzymes such as hypoxanthine guanine phosphoribosyl transferase (HGPRT), thiopurine methyltransferase (TPMT), and xanthine oxidase (XO) to form 6 thiouric acid, 6 methyl mercaptopurine (6MMP) and 6 thioguanine (6TGN) [2, 5]. Several metabolites of AZA have been held responsible for the occurrence of adverse events. High TPMT activity may cause elevated levels of 6MMP associated with hepatotoxicity. Diminished TPMT activity results in overproduction of 6TGN increasing risk of myelotoxicity [7]. Myelosuppression is a serious complication occurring in $7 \%$ of cases and cumulative incidence of severe pancytopenia is $1.1 \%$ [8]. Variations in TPMT activity occurs due to genetic polymorphism with studies showing $89.94 \%$ of individuals possessing high activity, 6-11\% intermediate and $0.3 \%$ low activity in the caucasian population. Homozygous forms of mutated TPMT alleles are at high risk for lethal myelotoxicity whereas heterozygous forms are advised to begin therapy at $50 \%$ recommended dose. In a study conducted in the indian population by Raju Murugesan et al., the genotype frequency of heterozygous mutants was $2.76 \%$ and no individuals with homozygous mutant 
alleles [9]. Although studies have showcased AZA induced pancytopenia related to TPMT deficiency, on the other hand, Colombel et al. have described myelotoxicity to be caused by factors other than TPMT deficiency [10]. Others suggest that blood monitoring is preferred as the best predictor as most myelotoxic patients while on AZA have normal TPMT activity plus the delay while awaiting its results [11]. It is hence recommended to monitor CBC and LFT every $2 \mathrm{w}$ for first $8 \mathrm{w}$ of AZA treatment and then every 3 mo [12].

\section{CONCLUSION}

This patient represents a probable case of azathioprine-induced severe myelosuppression with a Naranjo probability score of 6 . Physicians should be aware of the possibility of myelosuppression while prescribing azathioprine for immunosuppression. TPMT testing is the best predictor of bone marrow suppression; but due to its limited facility and expense, frequent monitoring of blood counts is preferred to avoid such adverse drug reactions.

\section{CONFLICTS OF INTERESTS}

Declared none

\section{REFERENCES}

1. Patel AA, Swerlick RA, McCall CO. Azathioprine in dermatology: the past, the present, and the future. J Am Acad Dermatol 2006;55:369-89.

2. Hadda V, Pandey BD, Gupta R. Azathioprine-induced pancytopenia. A serious complication. J Postgrad Med 2009; 55:139-40.

3. Fraser JA, Weyand CM, Newman NJ, Biousse V. The treatment of giant cell arteritis. Rev Neurol Dis 2008;5:140-52.
4. De Silva M, Hazleman BL. Azathioprine in giant cell arteritis/polymyalgia rheumatica: a double-blind study. Ann Rheum Dis 1986;45:136-8.

5. Solanki A, Choksi K, Patel S. Review article on treatment of pemphigus vulgaris. Int J Curr Pharm Res 2012;4:10-4.

6. Bisht R, Sharma D. Sjogren's disease: a comprehensive review in recent clinical and experimental findings in pathogenesis and pharmacotherapy. Asian J Pharm Clin Res 2011;4:32-9.

7. De Boer NK, Mulder CJ, Van Bodegravon AA. Myelotoxicity and hepatotoxicity during azathioprine therapy. Neth J Med 2005;63:444-6.

8. Gisbert JP, Gomollon F. Thiopurine-induced myelotoxicity in patients with inflammatory bowel disease: a review. Am J Gastroenterol 2008;103:1783-800.

9. Murugesan R, Vahab SA, Patra S, Rao R, Rao J, Rai P, et al. Thiopurine S-methyltransferase alleles, TPMT $\left({ }^{*}\right) 2,(*) 3 B$ and $(*) 3 \mathrm{C}$, and genotype frequencies in an Indian population. Exp Ther Med 2010;1:121-7.

10. Colombel JF, Ferrari N, Debuysree H, Marteau P, Gendre JP, Bonaz $\mathrm{B}$, et al. Genotypic analysis of thiopurine S-methyltransferase in patients with chron's disease and severe myelosuppression during azathioprine therapy. Gastroenterology 2000;118:1025-30

11. Seddik M, Texier F, Ferrari N, Cortot A, Libersa C, Broly F, et al. Thiopurine S-methyltransferase genotyping does not predict azathioprine-induced myelosuppression in Crohn's disease. Gastroenterology 2003;124:A192-3.

12. Bradford K, Shih DQ. Optimising 6 mercaptopurine and azathioprine therapy in the management of inflammatory bowel disease. World J Gastroenterol 2011;17:4166-73.

\section{How to cite this article}

- Jeslyn Mary Philip, Parvathypriya C, Christeena George, Meenu Vijayan. Azathioprine-induced pancytopenia-a case report. Int J Pharm Pharm Sci 2017;9(2):324-325. 